\title{
Las emociones experimentadas por los participantes en una competición matemática de resolución de problemas
}

\section{Emotions experienced by participants in a mathematical problem solving competition}

\author{
NÉlia Amado ${ }^{1}$ \\ namado@ualg.pt \\ Susana Carreira \\ scarrei@ualg.pt \\ Universidade do Algarve \& UIDEF, Instituto de \\ Educação, Universidade de Lisboa, Portugal
}

\section{Resumen:}

Las emociones aún son insuficientemente investigadas cuando se estudia la experiencia de los jóvenes estudiantes, principalmente en el que concierne a las emociones positivas que implican en la actividad de resolución de problemas. Por otro lado, hay muchos estudios que se relacionan con las dificultades, la ansiedad, la resistencia y la pasividad, a menudo asociadas con el fracaso en las matemáticas. La investigación ha mostrado que la actividad matemática no puede verse estrictamente cognoscitiva y libre de emociones; en el contrario, el sistema afectivo juega un rol central en el aprendizaje de las matemáticas.

En este artículo, presentamos resultados de un proyecto de investigación llevado a cabo en el contexto empírico de las competiciones matemáticas inclusivas que se realizan a través de Internet: SUB12 y SUB14. Se presentan y analizan datos de

\begin{abstract}
:
Emotions are still under-researched when exploring the mathematical experience of young students, particularly in what concerns the positive emotions involved in problem solving. On the other hand, there are many studies that deal with difficulties, anxiety, rejection and passivity, often associated with failure in mathematics. Research has shown that mathematical activity cannot be viewed as a strictly cognitive operation in which emotions are not involved; on the contrary, affective systems play a central role in learning mathematics. In this article, we present results from an empirical research project conducted in the context of inclusive mathematical competitions carried out through the Internet: SUB12 and SUB14. Data from a questionnaire, open-ended interviews, and e-mails exchanged during the competitions are presented and analysed. The conclusions of the study reveal
\end{abstract}

1 Dirección para correspondencia (correspondence address):

Nélia Amado. Faculdade de Ciências e Tecnologia, Universidade do Algarve. Campus de Gambelas. 8005-139 Faro (Portugal) 
Las emociones experimentadas por los participantes en una competición matemática de resolución de problemas

Nélia Amado y Susana Carreira

un cuestionario a los participantes, entrevistas abiertas y correos electrónicos intercambiados durante las competiciones.

Las conclusiones del estudio señalan que los estudiantes experimentan fuertes emociones positivas, a saber, entusiasmo, alegría, disfrute, orgullo y felicidad, asociadas a un desempeño exitoso en la resolución de problemas matemáticos, como era de esperar. Los resultados también muestran que las emociones negativas frente a la dificultad y el fracaso tienden a ser emociones suaves que parecen ser transitorias y se convierten en emociones positivas. Explicamos estos resultados en función de las características específicas del entorno cultural de estos concursos, es decir, fomentando la búsqueda de ayuda, proporcionando comentarios positivos y dando a los participantes la oportunidad de mejorar.

\section{Palabras-clave:}

Emoción; resolución de problemas; competiciones Matemáticas inclusivas; éxito; fracaso; dificultad; mejoramiento. students experienced strong positive emotions, namely enthusiasm, joy, enjoyment, pride and happiness, associated with a successful performance in mathematical problem solving, as could be expected. The results also show that negative emotions when it comes to facing difficulty and failure tend to be soft emotions that seem to be transient and turn into positive emotions. We explain these results based on the specific characteristics of the cultural environment of these competitions, namely encouraging help-seeking, providing positive feedback and giving the participants the chance to improve.

\section{Keywords:}

Emotion; problem solving; inclusive mathematical competitions; success; failure; difficulty; improvement.

\section{Résumé:}

Les émotions sont encore peu étudiées dans de cadre de la recherche sur l'expérience mathématique des jeunes étudiants, notamment en ce qui concerne les émotions positives liées à la résolution de problèmes. D'autre part, il existe de nombreuses études qui se concentrent sur les difficultés, I'anxiété, le rejet et la passivité, souvent associés à l'échec en mathématiques. La recherche a montré que l'activité mathématique ne peut être considérée comme strictement cognitive et émotionnellement libre; au contraire, le système affectif joue un rôle central dans l'apprentissage des mathématiques.

Dans cet article, nous présentons les résultats d'un projet de recherche mené dans le contexte empirique des concours mathématiques inclusifs qui ont lieu sur Internet, appelés SUB12 et SUB14. Les données collectées via un questionnaire, des interviews ouvertes aux participants et des courriers électroniques échangés au sein des concours sont présentées et analysées. Les conclusions suggèrent que les élèves expérimentent de fortes émotions positives, à savoir l'enthousiasme, la joie, le plaisir, la fierté et le bonheur, associées à la réussite dans la résolution de problèmes mathématiques, comme on pouvait le prévoir. Les résultats montrent également que des émotions négatives face à la difficulté et l'échec ont tendance à être des émotions légères qui semblent être transitoires et peuvent se transformer en émotions positives. Nous expliquons ces résultats en fonction des caractéristiques spécifiques de l'environnement culturel de ces concours, à savoir encourager la recherche d'aide, offrir une rétroaction positive et donner aux participants la chance de s'améliorer.

\section{Mots-clés:}

Émotion; résolution de problèmes; compétitions mathématiques inclusives; succès; échec; difficulté; amélioration.

Fecha de recepción: 9-5-2018

Fecha de aceptación: 3-10-2018 


\section{Introduction}

Over the last decades, the research in Mathematics Education has identified and investigated a number of factors that have an impact on students' success and failure in school mathematics. The affective dimensions involved in the teaching and learning process are currently acknowledged as being highly relevant. However, their short visibility makes it greatly concealed to the eyes of the educational community and to society in general and thus overlooked. This fact is highlighted by Goldin (2002), by noting the popular myth that mathematics is a purely intellectual activity in which emotions have no place. Moreover, it is reinforced by the fictional image of the mathematician as someone who is cold, severe, and without feelings. Such views have been refuted by many researchers from different fields, including Mathematics Education (e.g. Goldin, 2002) and Neuroscience (e.g. Damásio, 2000), according to whom the affective system takes a central role in the individual's activity while working on mathematics, which means that such role must not be seen as just a complement of the cognitive performance. In other words, affect and cognition are interconnected dimensions of the activity that influence each other (Ainley, 2006; Schweinle, Meyer, \& Turner, 2006; Walshaw \& Brown, 2012). In fact, there are studies that show the existence of interesting connections between affective aspects and the teaching and learning process, including the mathematical activities performed, namely in the case of proving where, for example, a feeling of appropriateness can be associated with, and strengthen, a behavioural schema to advance in the developing of a proof (Selden, McKee, \& Selden, 2010).

In the particular case of mathematical problem solving, the emotions experienced by students in that activity may range from the pleasure of being able to solve the problem to the frustration of not being able to understand what to do. In short, there is a recognisable multitude of affective factors involved in mathematics learning and in mathematical activity, which makes the study of affects a vast field of research involving concepts such as beliefs, attitudes, emotions, values and feelings, which can hardly be treated in isolation, as most researchers have long realised (Di Martino \& Zan, 2011).

In this article, we aim to uncover and examine some of the emotional features that exist within mathematical problem solving competitions named SUB12 and SUB14, addressing young students aged 10 to 14 and 
running through the Internet. The study of the affective aspects involved in mathematical problem solving, together with the solver's use of digital technologies and the mathematical creativity manifested in the solutions produced were the strands of the research conducted in the Problem@ Web Project (Carreira, Jones, Amado, Jacinto \& Nobre, 2016). This project elected the referred online competition as the empirical field of the research developed. Among the various affective aspects involved in the problem solving activity, we chose to focus our attention on the emotions manifested by the young participants during their participation in that competition.

Specifically, we were interested in the following issues that relate to the range of emotions and their connection to more or less pleasant experiences. We want to know: i) how the emotions before the difficulties in solving a problem are revealed; ii) how the emotions in failure or success in solving a problem are revealed; iii) how the emotions regarding the possibility of a second opportunity to correct a solution are revealed.

The selected questions are of interest to us because of the inclusive nature of the competitions that were the target of our research. Those are competitions in which there is an encouragement for help-seeking and where students are given a second chance when they fail to solve a problem, as long as they redo their answer within the set deadline. Finally, there is an interaction at a distance between the participants and the members of the organization, who provide regular feedback and encouragement in those competitions. Moreover, the problems proposed are chosen in order to be mathematical challenges of moderate difficulty.

\section{Conceptualizing emotion in education}

In the field of Mathematics Education, there is a growing awareness of the relevance and impact of many affective factors in the learning of mathematics - notably beliefs, attitudes and emotions.

There is also an apparent revitalized interest on the study of emotions in education, namely by looking at the emotions involved in the process of teaching and learning (Zembylas, 2007). According to Zembylas (2007), it is possible to distinguish three theoretical approaches to the study of emotions in education: i) emotions are understood as an individual experience, which means that they are intrapsychic 
and physiological and are a reaction of the individual to a given situation; ii) emotions are seen as a social construct that does not depend exclusively on the individual but rather depend on learned convictions or rules reflecting the ways in which emotions are experienced and expressed in light of socio-cultural norms; iii) emotions as interactional and performative in nature, therefore seeking to overcome the division between the psychological and the social, and postulating the embodiment of language and emotion. In this last perspective, the emotions are translated through bodily aspects (for instance, a smile) and through language (such as the tone of voice with which the words related to the emotions are pronounced), and are situated in the cultural context where the emotions take place (for example, inside the classroom or outside the classroom).

Emotions are always present in human experiences, but become more evident when they manifest in a more intense way. In particular, when solving problems young students experience a variety of more or less intense emotions, such as joy or sadness, frustration or satisfaction.

In theorizing the concept, several researchers have acknowledged the lack of agreement about the concept of emotion; however, they identified a number of central aspects where there seems to be a consensus (Hannula, 20002, 2004; Zan, Brown, Evans \& Hannula, 2006; DeBellis \& Goldin, 2006; Chacón, 2000):

- emotions relate to personal goals as they condense information about the progress achieved towards certain goals and about possible blockages;

- emotions involve physiological reactions which affect cognitive processing in a number of ways: they bias attention and trigger action predispositions;

- emotions play an important role in the human being coping and adaptation.

Hannula (2002, p. 28) synthesizes this set of basic characteristics of emotions when describing them as follows:

Emotions have three mutually independent readouts: adaptive-homeostatic arousal responses (e.g. releasing adrenaline in blood), expressive displays (e.g. smiling), and subjective experience (e.g. feeling sad) (Buck, 1999). 
It is also important to note that emotions are subject to change and a reason for those changes is the cognitive analysis that the subject makes of the situation (albeit unconsciously) considering the goals he/she has in mind. In this sense, the emotions related to cognitive goals are also called cognitive emotions (Hannula, 2002).

DeBellis and Goldin (2006) share this view by stating that an emotion designates an affective state with a precise cognitive content that is clearly accessible to consciousness (for example, we know why we feel fear, shame, or joy), even when it has a high intensity and a short duration. In fact, students are usually aware of their emotions and are able to identify their typical emotional reactions in different situations.

While a student is engaged in a mathematical activity, there is a continuous unconscious evaluation of the situation with respect to personal goals. This evaluation is represented as an emotion: proceeding towards goals induces positive emotions while obstacles that block the progress may induce anger, fear, sadness or other unpleasant emotions (Hannula, 2002, p. 29).

Those emotions that may be classified as positive emotions play a major role in educational contexts (Goetz, Frenzel, Hall, \& Pekrun, 2008). In the context of mathematics learning and performance, the most frequent emotions are enjoyment, anxiety, anger and boredom (Frenzel, Pekrun, \& Goetz, 2006). The academic emotions that are directly associated with learning and performance (Kleine, Goetz, Pekrun, \& Hall, 2005) may also be characterised according to two categories: valence and activation. While valence is considered as a bipolar dimension (positive vs. negative), activation is understood as unipolar and indicates the degree to which a given emotion is activated. Among positive emotions, enjoyment, pride, and hope are considered activating emotions, and relief and relaxation as deactivating emotions. Among negative emotions, anxiety, anger and shame or guilt are seen as activating emotions, whereas boredom and hopelessness are deactivating emotions.

Kleine et al. (2005) point out that it should not be assumed that positive emotions have a positive effect on learning or that negative emotions impact learning negatively. In turn, Neves and Carvalho (2006) argue that there are emotions more favourable to learning and others that are 
more unfavourable: persistent fear and confusion, resignation, prolonged uncertainty, lack of self-confidence (which leads to withdrawal and evasion) as well as boredom are examples of emotions that put obstacles to learning. Emotions conducive to learning include comfort, good humour, sense of well-being and pleasure, in articulation with the idea of challenge and persistence, states of acceptance and ambition; amazement and curiosity. As a general notion, the positive qualification when used to describe emotions has a connotation associated with a pleasant experience (Di Martino \& Zan, 2011).

Although for Damásio (2000) emotions, such as joy and sadness, are fundamentally complex sets of chemical and neural reactions to a stimulus, he also interprets them as essential to the cognitive processes, being able to favour them or to disturb them:

Knowing the relevance of emotions in the processes of reasoning does not mean that reason is less important than emotions, that it should be relegated to the background or should be less cultivated. On the contrary, when we look at the broad function of emotions, it is possible to highlight their positive effects and reduce their negative potential (p. 252).

In our perspective, emotions are not limited to the individual experience, distributed between body and mind, or to the socio-cultural experience; instead, we consider emotions, particularly in the context of mathematical activity, as reflecting the individual, but also the socio-cultural characteristics and norms of the context in which the action takes place (Amado, Carreira \& Ferreira, 2016). In the present study, some of the emotions manifested by participating students, such as the enjoyment for problem solving, are displayed in very different ways, both in relation to the success and pleasure of arriving at a correct solution and in less favourable situations, as in the case in which they feel difficulties to solve the problem. In fact, we are interested in identifying the manifestations of emotions (eventually positive or negative) in connection with the context of the mathematical activity of an inclusive competition, where help seeking and positive support are seen as playing a role in student's emotions while engaging in problem solving. 


\section{The empirical field: the problem solving competitions SUB12 \& SUB14}

As in many other countries, also in Portugal a number of mathematical competitions have emerged that seek to attract students to mathematics, promoting their enthusiasm and interest for this subject by involving them in appealing mathematical activities (Kenderov, Rejali, Bussi, et al, 2009; Stockton, 2012). Such competitions vary according to their duration and the type of mathematical activity involved, the age of the participants, the specific modes of running, the individual or team participation, etc. Despite this diversity of competitions with their own particular characteristics, they all converge towards the same general purpose - to make student's mathematical activity attractive to them (Kenderov et al., 2009).

Also included in this line are the Problem Solving Competitions SUB12 and SUB14, promoted by the University of Algarve, in Portugal. They are regional competitions aimed at all young students attending 5th and 6th grades (SUB12, 10-12 years) and 7th and 8th grades (SUB14, 13-14 years) who wish to participate. As it is generally recommended, the participation of any student in this type of initiative should be voluntary and not an imposition of teachers or parents (Protasov, Applebaum, Karp, Kašuba, Sossinsky, Barbeau \& Taylor, 2009). In addition, in order for a Competition, such as SUB12 and SUB14, to involve all students who wish to participate and ensure their success, it is necessary to pay special attention to the selection of activities - in this case, the problems to be proposed to the students. Instead of targeting the more gifted students, such as the case of the Mathematics Olympiads, the SUB12 and SUB14 competitions seek to involve all young people, and therefore they can be considered inclusive competitions. However, it is important to clarify the meaning of the inclusive term, which should not be confused with open to everyone. There are competitions that are open to all in the sense that anyone can participate, which have wide participation in terms of inflow numbers, but are not actually inclusive competitions. In fact, if the activities they propose to the participants are not accessible to the vast majority of potential contestants, then they fall into the category of non-inclusive competitions (Kenderov et al., 2009).

Inclusive competitions can naturally involve a very large number of 
students because the proposed activities are more accessible. The selection of activities to be proposed is directly related to the purpose of the inclusive competitions, which is distinct from the selective competitions. In fact, one of the distinguishing features is, as Kenderov et al. (2009) state, that the activities proposed in inclusive competitions should be appropriate to participants with different abilities:

It is important to choose the challenge, regarding form and complexity to suit the age, abilities and training of the participants. Challenges can be adapted to all levels of achievement. Even those with limited abilities can benefit from a challenging environment. They will be involved in the investigation and strategizing from the outset, and so gain an intimacy with the mathematics involved (p. 87).

The authors also stress the importance and, at the same time, the advantage of (inclusive) competitions not being dependent on the curriculum:

One of the problems with the classroom is that a school curriculum is rather restricted and cannot suit all. Competitions enable students to be exposed to other aspects of mathematics and for them to apply the skills they have to new situations. Competition enrich the learning experience of hundreds of thousands, in fact millions of students who participate in the inclusive competitions (Kenderov et al., 2009, p. 64).

In fact, one of the criteria for selecting good problems is finding them appealing to the participants, that is, that the participants like to solve them. In fact, we believe that this contributes to the challenging nature of the problems that are proposed in these competitions. Although the elaboration of the problems to be proposed to the participants takes into account the various recommendations in order to make them pleasant, challenging and accessible, this does not mean that the participants always see them has having the same degree of difficulty. For example, the problem "Sister and Brother's Ages" (Fig. 1) was one of the problems considered difficult by several participants in the SUB14. 


\section{Sister and brother's ages}

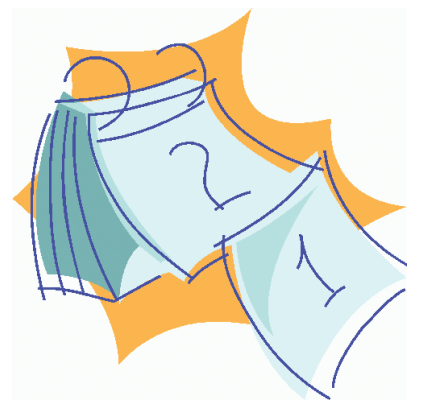

Soraia is three years younger than her brother is. Nine years from now, the difference between the brother and the sister's ages will remain the same but the product of their ages will increase 288 units. What are the ages of the sister and the brother now?

Do not forget to explain your process of solving the problem.

Fig 1. Problem \#4 from SUB 14 (edition 2011-2012).

The participation in (inclusive) mathematical competitions, especiaIly among the younger students, has demonstrated to have a positive influence on their motivation to learn mathematics (Freiman \& Vézina, 2006; Carreira et al, 2016). Moreover, the benefits of participating in mathematical competitions beyond the classroom - which are not only challenging but also intended to be appealing and mathematically enriching projects - include the development of a positive affective relationship with mathematics and problem solving. And this happens for both students who are high performers in school mathematics and those who experience a lower level of success (Freiman \& Vézina, 2006; Carreira et al, 2016). Satisfaction, self-efficacy, enjoyment, and interest in mathematics are some of the affective benefits of participating in mathematical competitions that have been identified in the existing research (Freiman \& Applebaum, 2011).

The problem solving competitions SUB12 and SUB14 take place outside the classroom in two phases: 1 ) the qualification, which works at a distance for six months through the Internet, and 2) the face-to-face final, held at the University for one day, involving students taking an individual problem solving test, coupled with a lecture for the parents and accompanying people and followed by a social gathering. 
The operating characteristics of the SUB12 and SUB14, especially during the qualification phase, support their inclusive nature. For example, all students are invited to step in regardless of their academic performance; families, friends and teachers are seen as partners in this participation since their involvement in helping the young students solving the problems proposed is encouraged; all approaches, strategies, representations and resources used to think about the problem and to express the solution are accepted; a formative and dialoguing feedback is offered to all participants, allowing them to review and improve their solutions and encouraging their persistence in solving the proposed problems. The most efficient, creative, elegant and interesting solutions are published on the webpage of the competitions, thus recognizing the participants' imagination, their creativity, effort and involvement in the problem solving activity.

\section{Data collection and analysis}

For decades, research in Mathematics Education has drawn almost exclusively on the use of questionnaires to investigate the influence of affective aspects in learning. Recent studies have started to consider the use of multiple collection instruments, such as interviews, focus groups, journals, observation and individual's narratives. This trend is visible in the researchers who adopt a more interactionist perspective like the one followed in this study (Zembylas, 2007).

The empirical context of this research does not facilitate direct observation since it involves an online distance competition running for six months in each edition. However, during the qualifying phase the collection of emails allows to access, through their written language and expressive icons, indications of the students' emotions and their relationship with the context of the competitions. Over the years, it was also possible to conduct interviews with participants as well as with older students who were former participants in past years (more than 10 interviews). In addition, we carried out a survey (available at http://tinyurl.com/problemaweb) that focused on the students participation in the competition, involving aspects related to the use of technologies and to the affective character of such activity. The items related to the affective dimensions sought to know the students' opinions about the proposed 
challenges, the difficulties felt in solving each challenge, the importance of the participation in their lives, the most pleasant/unpleasant factors present in the competitions and the emotions experienced during their participation. Many of the questions were subdivided into sub-questions that were answered on a 4 or 5 -level Likert scale. After a validation process, through testing the instrument with students of the same age level, and submitting it to the review of collaborating teachers, the questionnaire was delivered by email to all the participants in one edition of the two competitions. The total of answers collected was 350, corresponding to a return rate of around $20 \%$ in SUB12 and $17 \%$ in SUB14, which was considered acceptable for an online survey where you do not have direct access to the respondents. The instrument included a first part referring to demographic data, such as age, gender, and school grade. Being mainly informative, those data were not actually subject to specific analysis, as we were not aiming to make possible comparisons by gender or age group, for example. Although the representativeness of the sample is not claimed, the data are faithful, in gender, age and school grades distribution, to the universe of participants in the two competitions in the year of the survey application.

The data analysis followed an interpretative approach. We started by establishing interconnections between different types of data, taking the results of the survey as the primary basis. Such results were cross-referenced with open-ended interviews focused on the participants' experience at various times and on several aspects of the competition, including the qualification and the final. Finally, we used data from the emails exchanged with the participants for gathering elements about what they refer in relation to their difficulties, desires and expectations, and their expression of emotions through written language and emoticons.

\section{Results and discussion}

In the following we describe the data that reveal some traces of the students' emotions related to the following focuses: i) their enjoyment of mathematics and problem solving; ii) what they feel to be the ideal degree of difficulty in the problems; iii) what they feel when they fail to solve a problem; iv) how they see the fact of having a second chance; v) what they feel when they can correctly solve a problem. The analysis starts 
from a reading of the results of the survey and continues with the combination of other data that helps to illuminate and complete the first data.

\section{Enjoyment of mathematics and problem solving}

Liking or disliking mathematics is perhaps the most frequent question when people refer to this school subject. No other subject seems to be as fertile in provoking reactions, attitudes, and emotions as mathematics. The enjoyment of mathematics was therefore one of the first questions we posed to the participants in the survey (Fig. 2). It is interesting to note that not all of them refer liking this discipline. About $21.4 \%$ of the respondents even say that they do not like mathematics or like it very little; however, this fact did not prevent them of getting involved in the competition.

The percentage of respondents who said they like mathematics or like it very much is high; indeed, about $48 \%$ of the respondents indicate that they are very fond of mathematics and about $30.6 \%$ just declare enjoying mathematics. Such results are not surprising, when considering that the students who participate in these competitions are doing it in a voluntary basis and therefore they seem to find in it some attractive element, among which the enjoyment of mathematics obviously play a role.

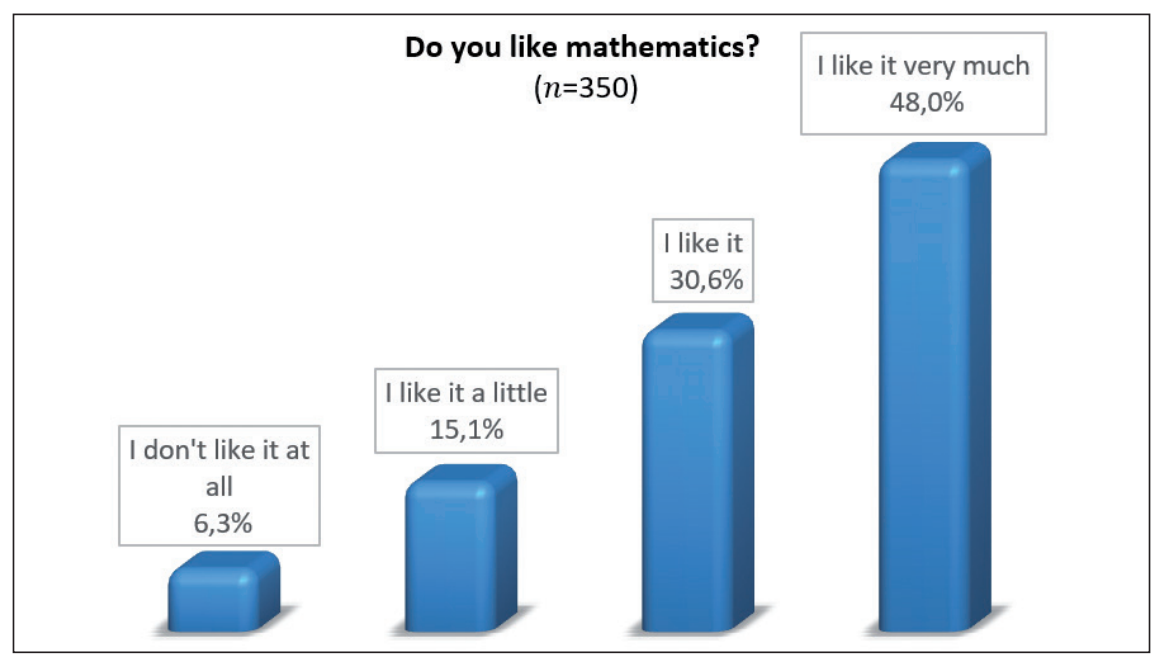

Fig. 2. Student's answers on enjoying mathematics.

Also, according to the respondents, the enjoyment of problem solving does not deviate much from the enjoyment of mathematics (Fig. 3). As 
far as the enjoyment of mathematical problem solving is concerned, the data in Figure 3 shows that around $37.7 \%$ like solving mathematical problems and $39.4 \%$ like it very much. We will now look further into the meaning of enjoyment of problem solving, by drawing on data obtained from interviews. The anonymity is preserved, being the various interviewees designated by a letter code.

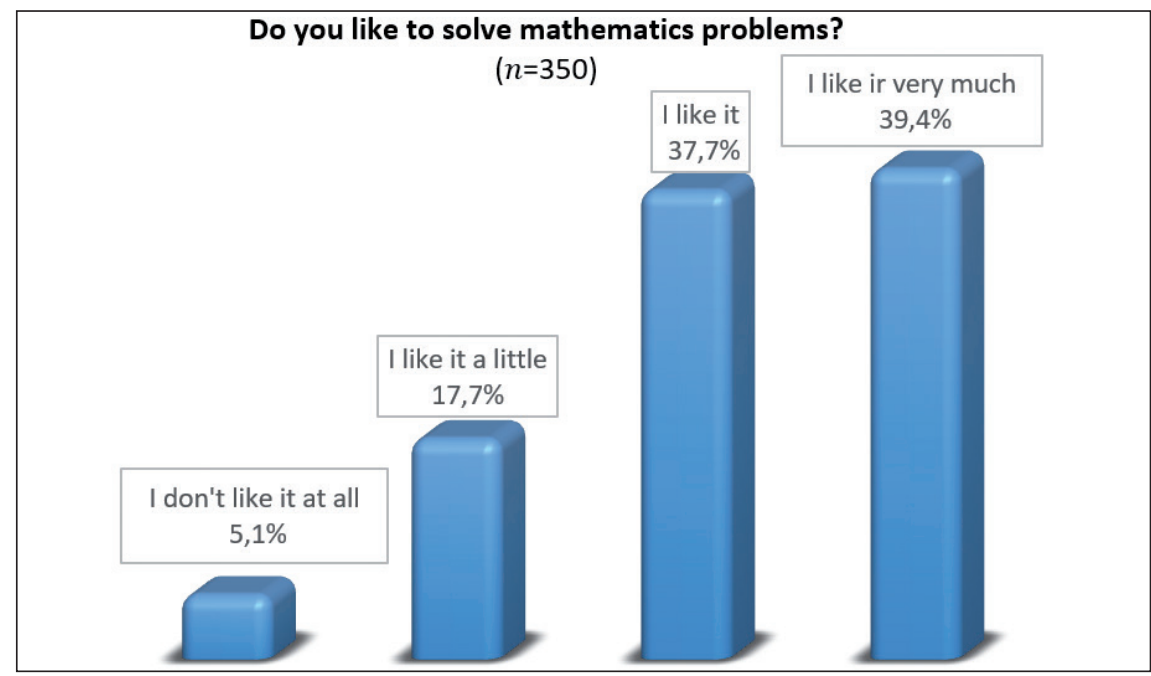

Fig. 3. Student's answers on enjoying mathematical problems.

The interviews conducted with some participants and former participants in the competitions helped us to better understand what the enjoyment of problem solving means. Although some do not say much more than the effusive statement "I like to solve problems!" (Participant J), others are able to elaborate a little more about what they feel, showing, for example, a liking that covers all kinds of problems indiscriminately and also an appreciation for challenging nature of the problems:

I liked solving the problems, but I do not remember any in particular. I liked them all. (Participant RV)

I liked the problems. They really offered a good challenge to be solved. (Participant X)

Another participant was equally pleased with all the problems, including those she considered the most difficult ones, saying: 
Overall, I enjoyed solving all the problems. I remember there were one or two problems more difficult and so... Some took me days thinking about them... (Participant MH).

\section{The best level of difficulty in the challenges}

As previously mentioned, the problems proposed in the competitions are intended for a large number of students and with different levels of knowledge, abilities and school performance. Each individual faces the challenge differently: something for a person may be an easy and/or interesting challenge and for another it may be very difficult and/or uninteresting. Because of this, and bearing in mind the purposeful distance between the problems presented in the competitions and the official curricula, the problems presented involve different mathematical topics and may be judged by the participants as easy, of medium difficulty or difficult. Thus, we tried to know what the preference of the students was in relation to the degree of difficulty of the problems they were asked to solve in the competitions. The graph in Figure 4 shows that the majority of respondents, i.e. around $49.1 \%$, preferred moderate challenges, but there were clearly some students who preferred the more difficult ones, i.e. around $26.6 \%$, and yet $24.3 \%$ of the respondents revealed preferring the easiest ones. These results are actually compatible with the nature of the competitions that is assumed to be inclusive.

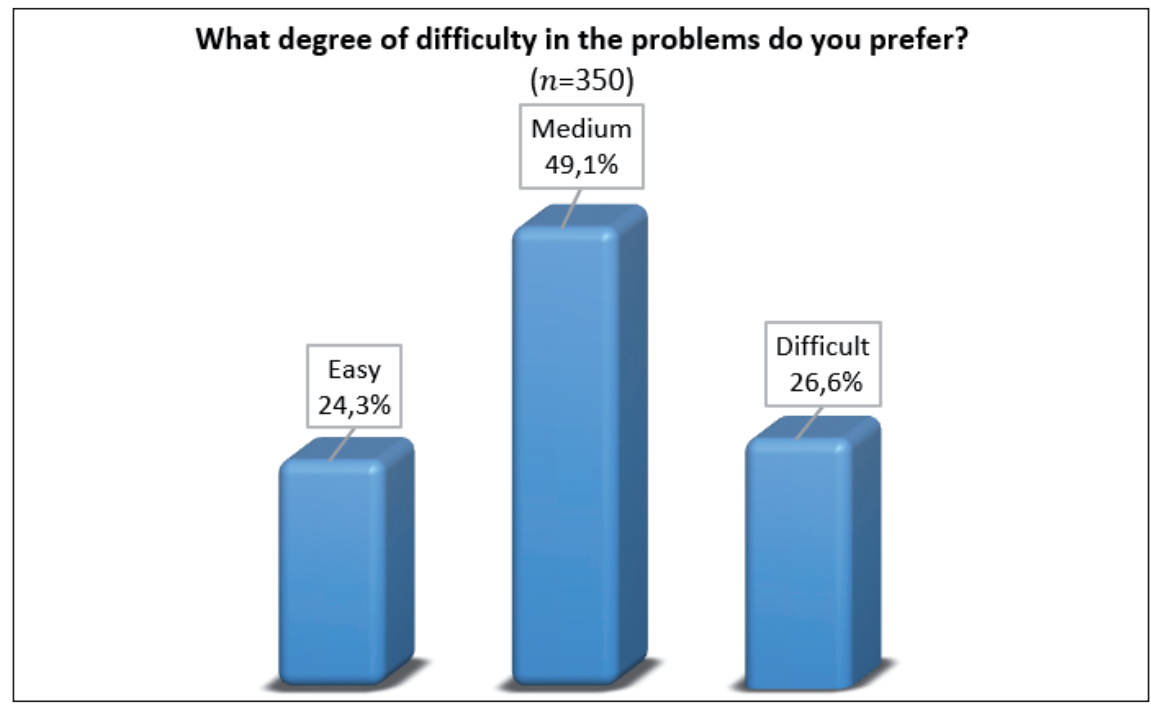

Fig. 4. Student's answers on the degree of difficulty they preferred in a problem. 
In fact, the data from the questionnaire show that the participants prefer moderate challenges, which is in line with what the research literature suggests (Turner \& Meyer, 2004). Although it was more frequent to get email messages from participants referring that a particular problem had been difficult, through the interviews we had the opportunity to listen to some students who found the challenges generally easy.

Ah, this is easy. I can solve it ... (Participant J).

Some students had the opportunity to participate in the competitions over four years (first in SUB12 and after in SUB14) and this experience was reflected in the way they began to face the challenges. One interviewee pointed out that the difficulty of the challenges seemed to be changing over time and he explained the reasons for that sensation:

In the last year I found it to be very easy. It was not that easy, but in fact the difficulties I had before disappeared. (...). In the end, I found that it was much easier. (...). Yes, because, of course, our reasoning is trained. (Former Participant JC).

This interviewee acknowledges that over time, he was facing the mathematical challenges in a different way; from year to year it was easier for him to solve the problems, but he also concluded that it was not the problems that became easier or more difficult. And he went on explaining that reasoning can be trained, which reveals his understanding that one can get better at solving problems by solving problems. Other participants even claimed to appreciate the difficult problems:

I particularly liked some of the more difficult ones. My mother did not understand how I got to the answer and she thought I was wrong. I used to make small bets with her (€5 or €10). I do not remember ever having lost. (Participant RV)

The words of this boy also show that the degree of difficulty of a problem did not hamper his enjoyment of problem solving:

It may be difficult and I still like it; [being difficult] has nothing to do with liking or not liking. (Participant RV) 
This participant also highlights a characteristic that made him like more or less of a problem: the time it took him to solve it. The longer it took him to solve a problem, the less he liked it, as he stated:

I did not like those that took me a long time to arrive at the answer. I remember one that even my maths teacher had a hard time solving it. I only got the solution with help. (Participant, RV).

This result shows that although moderate challenges are important, the issue is not only a question of moderation but also of the time spent to solve a problem.

\section{Emotions in the face of difficulties}

Related with the enjoyment in solving problems and the demands on that activity, namely justifying a preference for the easier or the more difficult ones, it is interesting to identify some aspects related to the emotions experienced by the participants in view of their difficulties in problem solving.

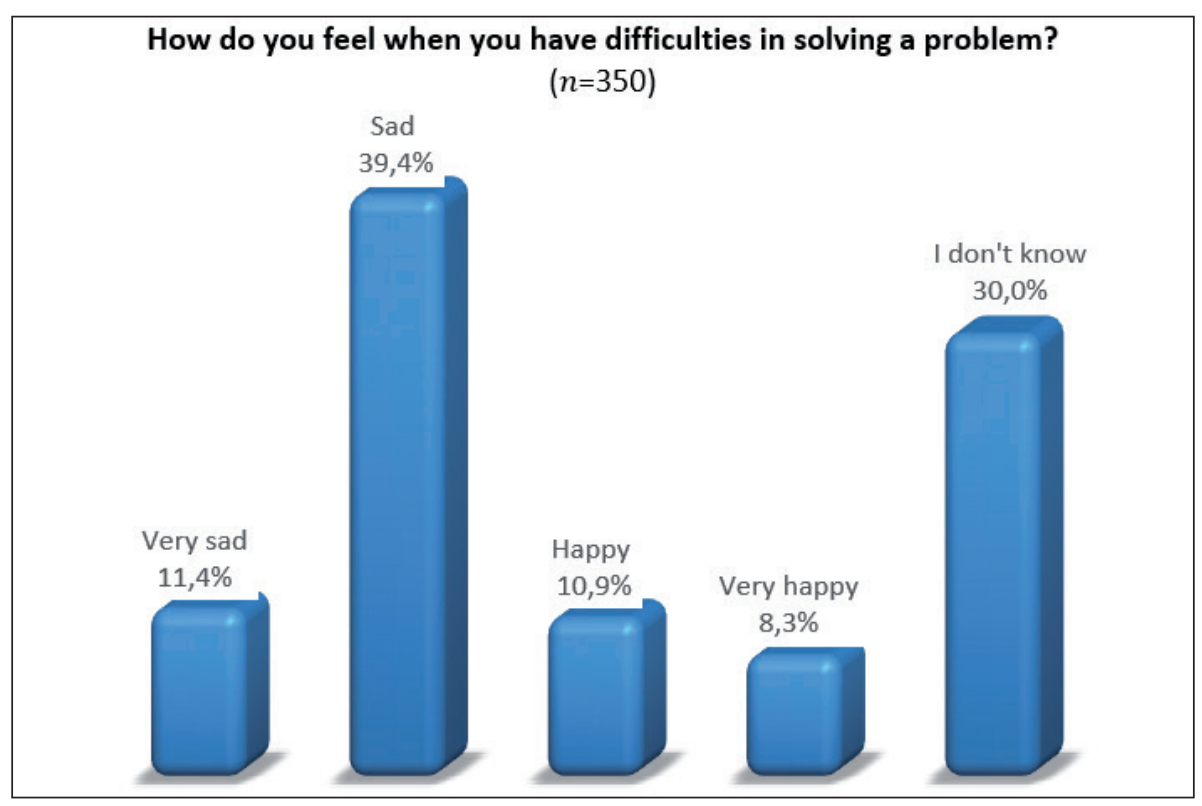

Fig. 5. Student's answers on the emotions related to the difficulty felt. 
Las emociones experimentadas por los participantes en una competición matemática de resolución de problemas

Nélia Amado y Susana Carreira

The emergence of difficulties seems not to be felt as pleasant; in fact, about $39.4 \%$, reveals feeling sad when having a hard time in solving a problem. However, $30 \%$ of the respondents say they do not know how they feel about the difficulties. This percentage of participants who do not seem to be sad or very sad could be explained by the possibility of requesting help to the organizing team of the competitions and, therefore, this could mean that they do not feel threatened by the difficulties they may face in their participation. Some of the messages sent by participants requesting help contain symbols that illustrate a smile, such as the following message (Fig. 6) where the participant sends a smile twice.

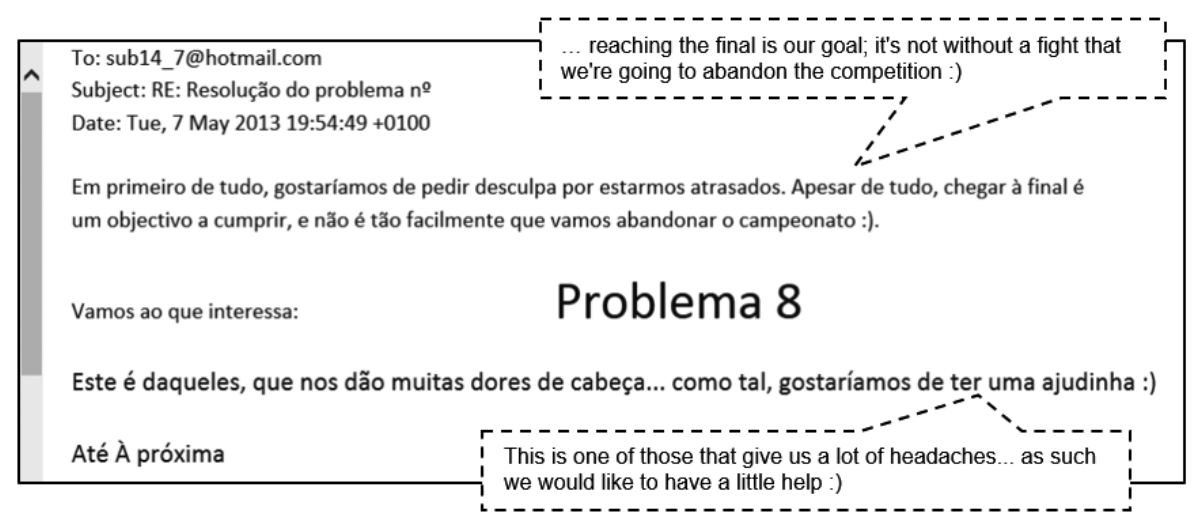

Fig. 6. Email message of a participant having difficulties but using smiles.

The expression "this problem gave us a lot of headaches" came up with some frequency when the participants felt difficulty in solving a certain problem. However, such difficulties do not always seem to have given rise to an emotion of sadness. Also the message presented in Figure 7 shows that the participant felt difficulty in solving the problem, but he decided nevertheless to include an emoji of a smirking face before presenting his resolution. 
Olá de novo... pedimos desculpas pois apesar de estarmos determinados... temos demorado algum tempo a resolver os problemas... ainda estamos de férias (o calendário da nossa escola é diferente) por isso vamos empenharmos a pôr a resolução do problemas em falta...

\section{Problema 5}

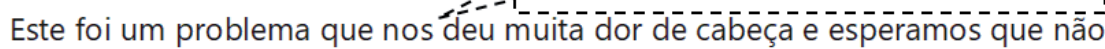
nos dê mais... vamos a isto:

Fig. 7. Email message of a participant speaking about the difficulties.

Also in the message of Figure 8, the participant admits that she felt some difficulties, by highlighting those words with a colour, but she then explains that with hard thinking she managed to overcome her difficulties. In the end, she writes "thank you" in several languages and uses a new colour in the text. These messages lead us to think that the participants seem to cope quite well with the difficulties, not refraining from revealing them, and in some cases describing how they have overcome them.

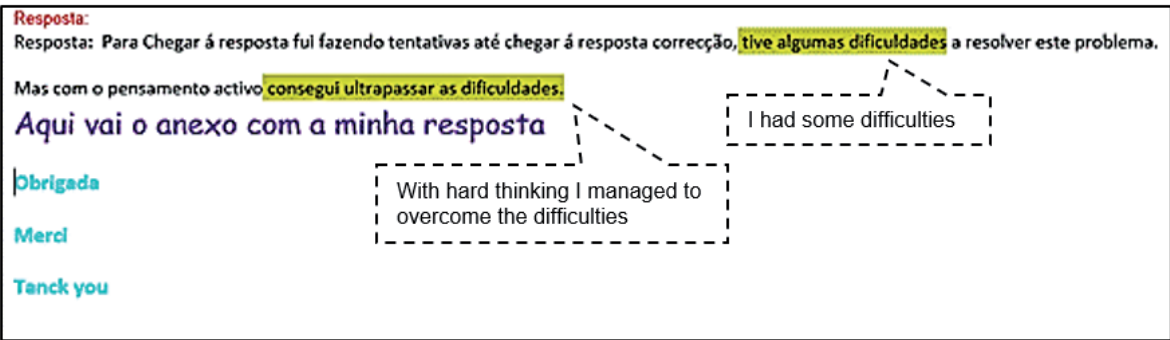

Fig. 8. Email message of a participant speaking about the difficulties overcome.

\section{Emotions in dealing with failure}

One of the features of this competition is providing feedback to all participants. If the answers to the problems that students submit are not correct, clues are offered so that participants can begin to outline a new strategy for solving the problem and resubmit it within the two-week period stipulated for solving each problem. The following is an example of a reply to a participant that shows the kind of feedback and hints that were given: 
Las emociones experimentadas por los participantes en una competición matemática de resolución de problemas

Nélia Amado y Susana Carreira

\section{Hi Mariana,}

We received your answer to the problem 10 but you'll have to think a little more.

\section{HERE IS A HINT FROM THE SUB14}

Starting by organizing the data is an excellent idea, especially in this kind of problem! We found a flaw at the very beginning that has consequences in your subsequent reasoning. Notice that you can have three different combinations with Mayonnaise: Mayonnaise + mustard / Mayonnaise + ketchup / Mayonnaise + mustard + ketchup.

With the number of burgers with Mayonnaise + mustard being 17, your calculation allows you to find the number of burgers with Mayonnaise + ketchup and with Mayonnaise + mustard + ketchup!

There is a strategy that helps to solve these problems: a Venn diagram. Do you know it? (http://pt.wikipedia.org/wiki/Diagrama_de_Venn)

We look forward to your corrected answer.

Hope to hear from you soon,

SUB14

According to graph of Figure 9, 44.9\% of the respondents feel sad and $18.3 \%$ feel very sad when they receive a message informing that the solution is not correct. The data from the questionnaire may now be complemented with the content of some of the e-mail messages exchanged throughout the competition.

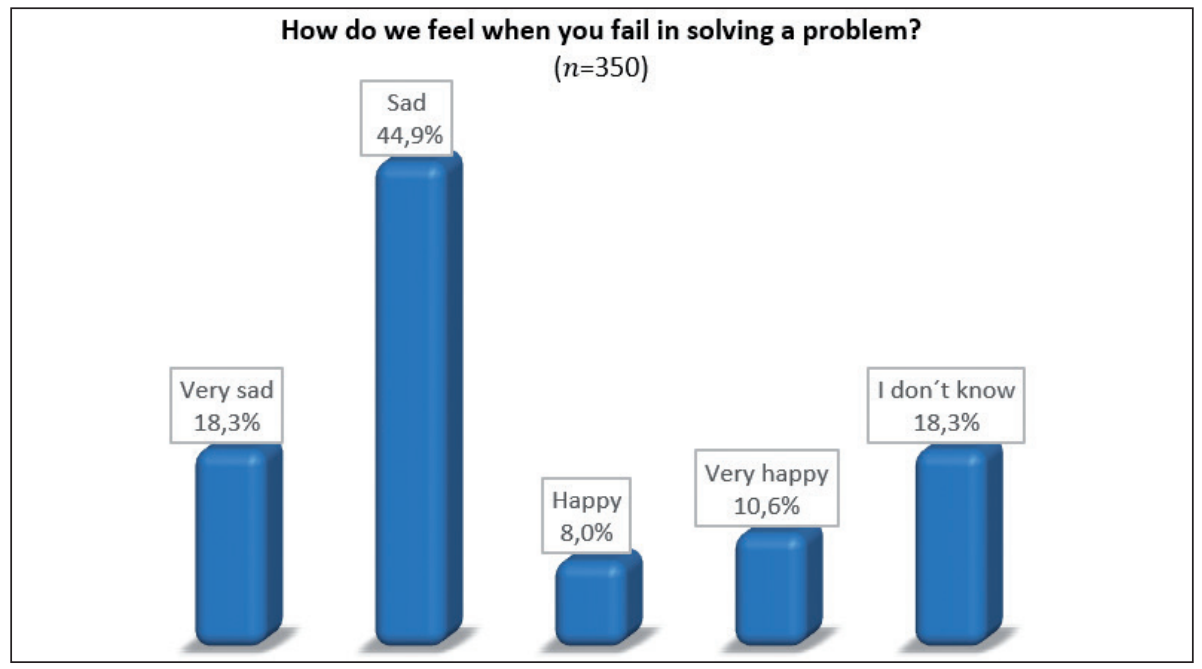

Fig. 9. Student's answers on the emotions related to failure. 
In the email shown in Figure 10 in which the participant reveals that the group is sad about not being able to guess the correct solution to the problem and reinforces his feeling with an emoji.

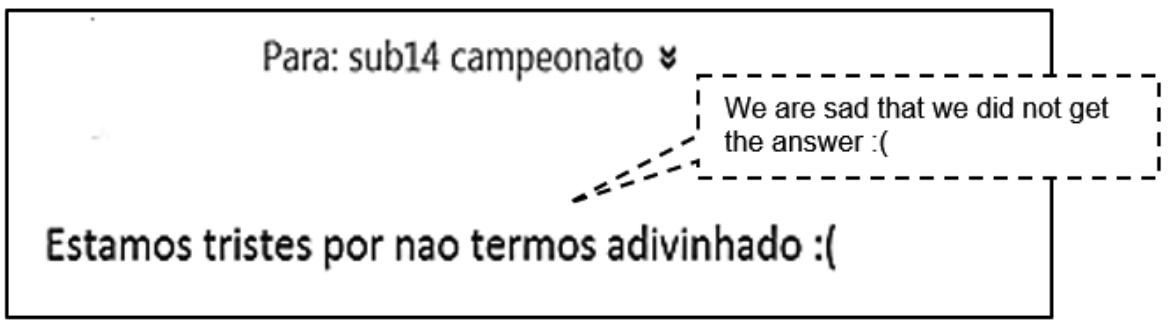

Fig. 10. Email message of a participant revealing sadness.

However, another participant said that knowing that his answer was not correct did not change his willingness to participate in the competition:

I continue with the same will, if it was wrong, It's because I did something wrong, so I do it again (Participant R).

\section{Having the chance to improve}

As mentioned before, all the participants have the opportunity to improve and submit their solution until completely correct, within the stipulated time. The participants who do not have a correct resolution get the opportunity to review and improve their work, often with the support of the organization. This opportunity differs from what happens traditionaIly in school life and it seems to be greatly appreciated by the students.

In fact, $36.3 \%$ of respondents report feeling happy and $25.1 \%$ very happy about having a new opportunity to get the correct solution (Fig. 11). In general, participants take advantage of this opportunity, usually accepting an aid offered by the organization or that they themselves seek as shown by some email messages. 


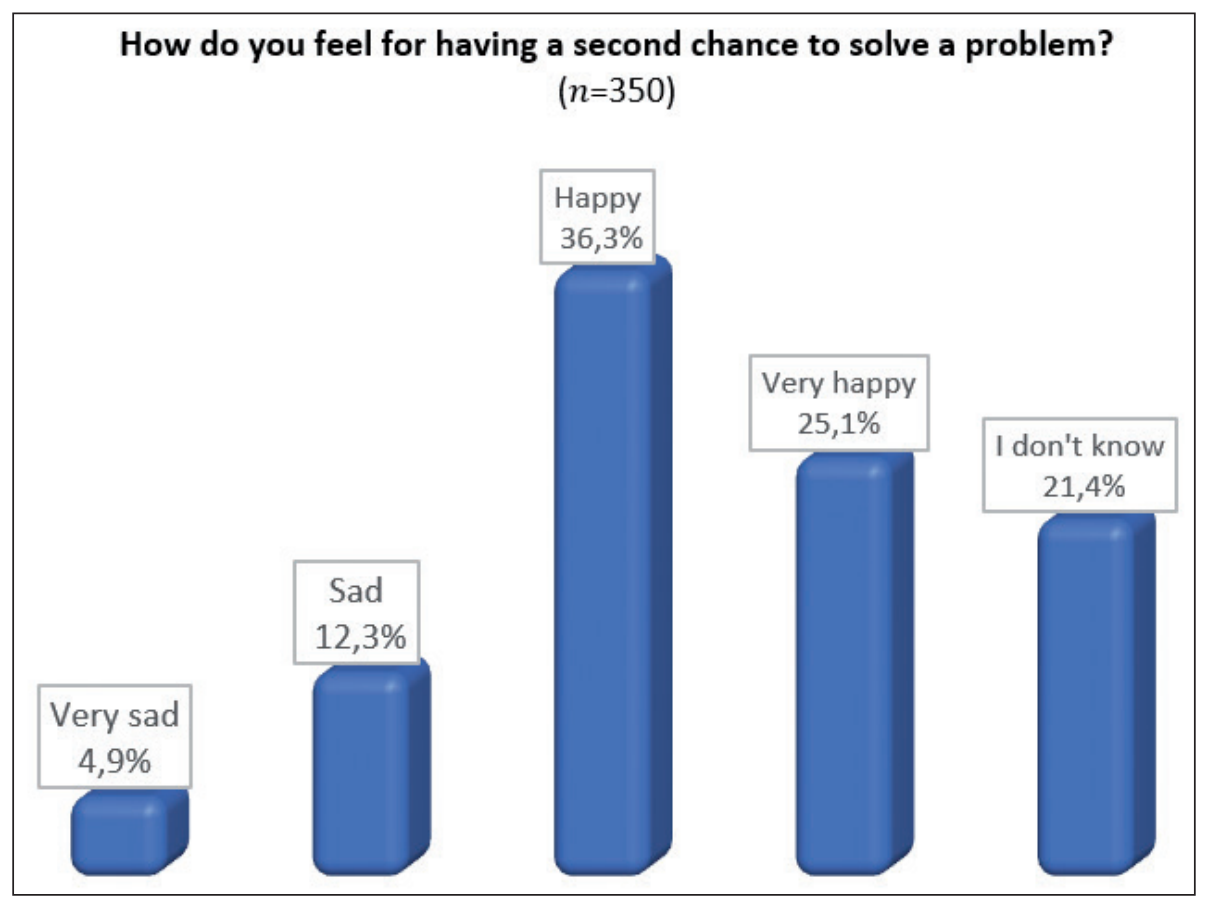

Fig. 11. Students' answers on their emotions about getting a second chance.

Through the interviews, we gathered opinions that show two things worth highlighting: the opportunity to review the resolution and the help provided by the organization as useful to overcome the mistakes initially made.

I think it was good because they do not offer the complete solution, nor too much detail, but they offer a small detail that helps the students to continue their work.

Yes, it is good because if students fail to solve a problem and if they send the wrong solution, obviously they will continue to have always the wrong answer. If they offer a help, there's the push we need.

These comments show how the interaction between the organization and the participants based on constructive feedback avoids frustration and the feeling of punishment. On the contrary, participants are encouraged to persist and to believe that they will be able to solve the problem. 


\section{Emotions in a successful situation}

Sending the correct resolution and receiving a confirmation very quickly is apparently the desire of almost all the respondents. About $64 \%$ of students surveyed state they feel very happy about receiving an answer stating that the solution is correct and about $27.1 \%$ feel happy (Fig. 12).

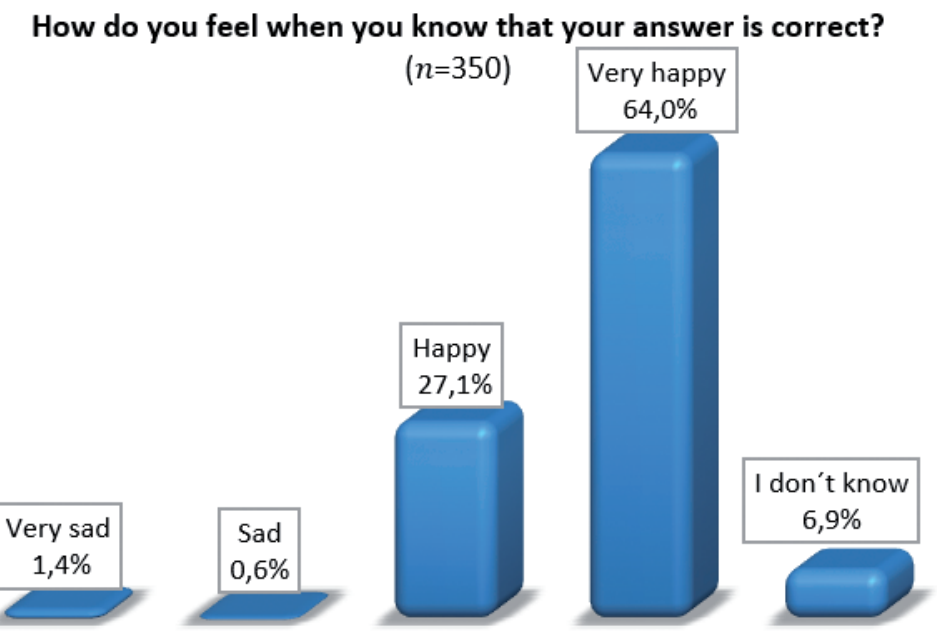

Fig. 12. Students' answers on their emotions on succeeding to solve a problem.

Many of the e-mail messages appealed to a quick response from the organization, thus revealing a great deal of interest and satisfaction in receiving approval. Several messages asking the organization for a reply illustrated several emotions. The following message was sent by a student who often sent emails expressing emotions (Fig. 13).

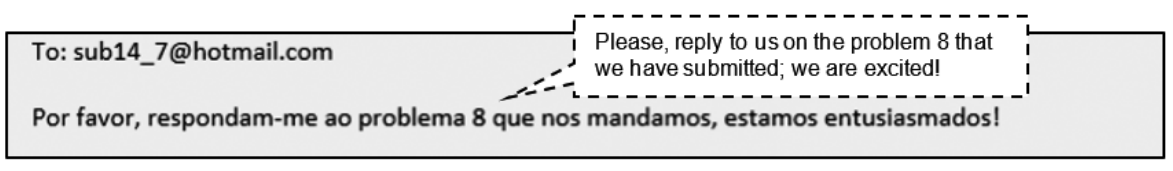

Fig. 13. Email message from a group of contestants asking for a quick reply to their submission.

Another group of participants in SUB 12 showed their happiness at receiving the message stating that they had hit the last problem of the year and they immediately expressed the desire to participate the following 
Las emociones experimentadas por los participantes en una competición matemática de resolución de problemas

Nélia Amado y Susana Carreira

year, again adding smiles in their text (Fig. 14). Thus, empathy and enjoyment in participating in the competitions are clearly reinforced by the joy of success over participation.

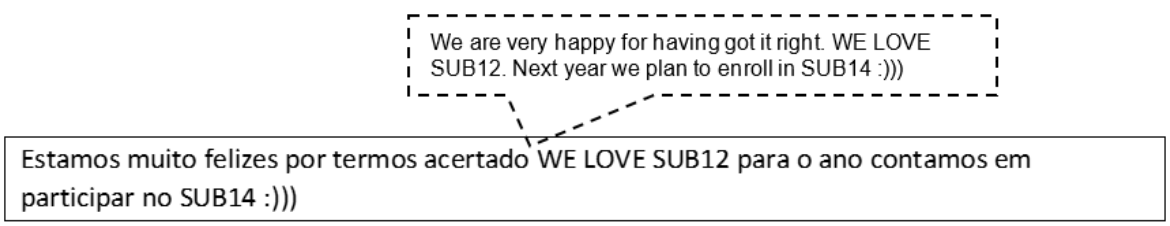

Fig. 14. Email message showing happiness for having the solution right.

Also another participant in SUB12, after receiving a confirmation that all her solutions were correct until that time, reveals loving to participate in the competition (Fig. 15). Again, there is a clear association between the feeling of success in solving the problems and the emotion of happiness and enjoying the participation.

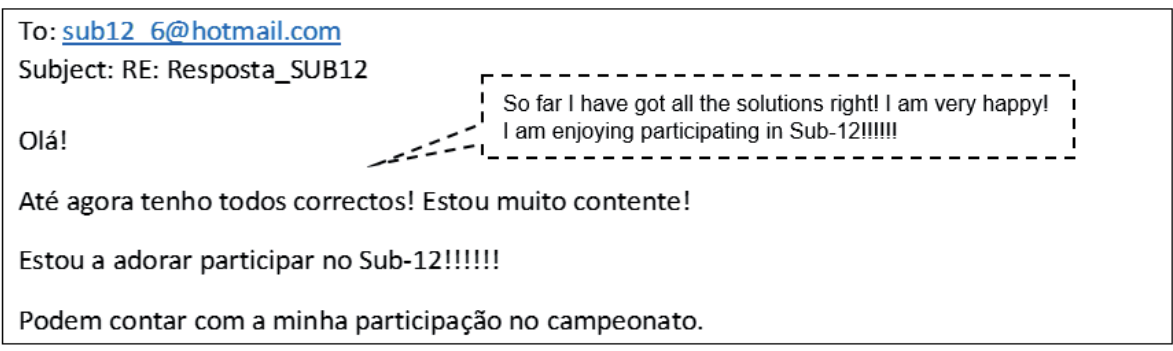

Fig. 15. Email message showing happiness for having several solutions correct.

From the interview data, we obtained other testimonies from the participants about the emotions of joy and pride related to their success in solving problems:

Joy to be participating and receiving an email saying that I had the right solution. (Participant D)

I felt what anyone would feel: joy, for solving the problem and pride too. (Participant X) 


\section{Final comments}

In this study, we aimed to identify and understand the manifestations of emotions (positive or negative) experienced by the participants in an inclusive mathematical problem solving competition. The data presented focused on the emotions related to more or less pleasant experiences within the problem-solving activities and were interpreted in the light of the fundamental characteristics of the context of the mathematical activity, which, in this case, promotes the help seeking, the positive support, the feedback, and the opportunity to improve.

The SUB12 and SUB14 mathematical competitions are clearly a fruitful field of emotions. In fact, as showed in the literature, students when solving problems experience a variety of more or less intense emotions, such as joy or sadness, frustration or satisfaction (Schweinle et al., 2006).

One of the results obtained from the data is that the students reveal several emotions with different degrees of intensity that are in tune with their more or less agreeable experiences. When participants experience successful situations in problem solving activities, their (positive) emotions of satisfaction, joy, happiness, and enjoyment seem to be intense. When less pleasant situations arise, such as difficulties in solving a problem or failure to obtain the solution, seemingly unfavorable to the learning and success (Neves \& Carvalho, 2006), our data shows interesting results.

In a way, in opposition to what is described repeatedly, in the context of our research, we verify that:

- Difficulties in solving problems, often translated as "headaches" in the students' language, seem to be viewed by the participants in a light manner;

- Participants tend to prefer problems of moderate difficulty although there is no direct relationship between difficulty and more or less enjoyment;

- Although there is mostly sadness because of the difficulties, many participants do not associate difficulties with happiness or sadness;

- Failure in solving a problem causes sadness in many students, but this sadness does not reveal great intensity and seems to be transitory;

- This sadness does not seem to be an emotion that leads to frustration or rejection, but rather it seems to evolve into positive emotions like hope, confidence and determination to improve. 
Las emociones experimentadas por los participantes en una competición matemática de resolución de problemas

Nélia Amado y Susana Carreira

In short, we argue that in the cultural context of the inclusive competitions SUB12 and SUB14, participants also undergo unpleasant experiences but the associated negative emotions are soft and tend to evolve in a positive direction.

In our view, this happens because these competitions offer the participants, through continuous and systematic feedback from the organization, several opportunities to arrive at the solution of a mathematical challenge. Eventually, this transforms the emotion of sadness for not being able to solve the problem into a more positive emotion through the exchange of messages and feelings (expressed by emoticons) with the organization, or the discussion with parents, colleagues and friends of a new approach to the problem.

As shown, the fact that a student does not solve a problem at first seems not to become an obstacle to his participation in the competition. On the contrary, this cultural context (Zembylas, 2007) allows intense positive emotions and soft negative emotions in student's mathematical activity that explain the success, the enjoyment and the will to endure of most of the participants.

\section{References}

Ainley, M. (2006). Connecting with learning: Motivation, affect and cognition in interest processes. Educational Psychology Review, 18(4), 391-405.

Amado, N., Carreira, S., \& Ferreira, R. (2016). Afeto em competições matemáticas inclusivas. A relação dos jovens e suas famílias com a resolução de problemas. Belo Horizonte: Autêntica, Brasil.

Carreira, S. Jones, K., Amado, N., Jacinto, H., \& Nobre, S. (2016). Youngsters Solving Mathematical Problems with Technology: The Results and Implications of the Problem@Web Project. New York, NY: Springer.

Chacón, I. M. (2000). Matemática emocional: los afectos en el aprendizaje matemático. Madrid: Narcea.

Damásio, A. (2000). O erro de Descartes - emoção, razão e cérebro humano. (21ª Ed.). Mem Martins: Publicações Europa-América.

DeBellis, V. A., \& Goldin, G. (2006). Affect and meta-affect in mathematical problem solving: A representational perspective. Educational Studies in Mathematics, 63(2), 131-147.

Di Martino, P., \& Zan, R. (2011). Attitude towards mathematics: a bridge between beliefs and emotions. ZDM - Mathematics Education, 43, 471-482.

Freiman, V., \& Applebaum, M. (2011). Online mathematical competitions: Using virtual marathon to challenge promising students and to develop their persistence. Canadian Journal of Science, Mathematics and Technology Education, 11(1), 55-66. 
Las emociones experimentadas por los participantes en una competición matemática de resolución de problemas Nélia Amado y Susana Carreira

Freiman, V., Véniza, N. (2006). Challenging virtual mathematical environments: The case of the CAMI Project. Pre-conference paper of the Study Conference for ICMI Study 16 - Challenging Mathematics In and Beyond the Classroom. Retrieved from http:// www.amt.edu.au/icmis16pcanfreiman.pdf.

Frenzel, A. C., Pekrun, R., \& Goetz, T. (2006). Perceived learning environment and students' emotional experiences: A multilevel analysis of mathematics classrooms. Learning and Instruction, 17, 478-493.

Goetz, T., Frenzel, A. C., Hall, N. C., \& Pekrun, R. (2008). Antecedents of academic emotions: Testing the internal/external frame of reference model for academic enjoyment. Contemporary Educational Psychology, 33, 9-33.

Goldin, G. (2002). Affect, meta-affect, and mathematical belief structures. In G. Leder, E. Pehkonen \& G. Törner (Eds.), Beliefs: A hidden variable in mathematics education? (pp. 59-72). Dordrecht, The Netherlands: Kluwer.

Hannula, M. (2002). Attitudes towards mathematics: Emotions, expectations, and values. Educational Studies in Mathematics, 49, 25-46.

Hannula, M. (2004). Affect in mathematical thinking and learning. (Doctoral dissertation). University of Turku, Finland. Retrieved from: https://www.academia.edu/200462/ AFFECT_IN_MATHEMATICAL_THINKING_AND_LEARNING

Kenderov, P., Rejali, A., Bussi, M. G., Pandelieva, V., Richter, K., Maschietto, M., Kadijevich, D., \& Taylor, P. (2009). Challenges beyond the classroom - Sources and organizational issues. In E. J. Barbeau \& P. Taylor (Eds.), Challenging mathematics in and beyond the classroom: The 16th ICMI Study (pp. 53-96). New York, NY: Springer.

Kleine, M., Goetz, T., Pekrun, R., \& Hall, N. (2005). The structure of students' emotions experienced during a mathematical achievement test. ZDM - Matematics Education, 37(3), 221-225.

Neves, M., \& Carvalho, C. (2006). A importância da afectividade na aprendizagem da matemática em contexto escolar: Um estudo de caso com alunos do $8 .^{\circ}$ ano. Análise Psicológica, 24(2), 201-215.

Protasov, V., Applebaum, M., Karp, A., Kasuba, R., Sossinsky, A., Barbeau, E., \& Taylor, P. (2009). Challenging problems: Mathematical contents and sources. In E. J. Barbeau \& P. Taylor (Eds.), Challenging mathematics in and beyond the classroom: The 16th ICMI Study (pp. 11-51). New York, NY: Springer.

Schweinle, A., Meyer, D., Turner, J. (2006). Striking the right balance: Students' motivation and affect in elementary mathematics. Journal of Educational Research, 99(5), 271-293.

Selden, A., McKee, K., \& Selden, J. (2010). Affect, behavioural schemas and the proving process. International Journal of Mathematical Education in Science and Technology, 41(2), 199-215.

Stockton, J. C. (2012). Mathematical competitions in Hungary: Promoting a tradition of excellence \& creativity. The Mathematics Enthusiast, 9(1-2), 37-58.

Turner, J., \& Meyer, D. (2004). A classroom perspective on the principle of moderate chaIlenge in mathematics. Journal of Educational Research, 97(6), 311-318.

Walshaw, M., \& Brown, T. (2012). Affective productions of mathematical experience. Educational Studies in Mathematics, 80(1-2), 185-199. 
Las emociones experimentadas por los participantes en una competición matemática de resolución de problemas

Nélia Amado y Susana Carreira

Zan, R., Brown, L., Evans, J., \& Hannula, M. (2006). Affect in mathematics education: An introduction. Educational Studies in Mathematics, 63(2), 113-121.

Zembylas, M. (2007). Theory and methodology in researching emotions in education. International Journal of Research \& Method in Education, 30(1), 57-72. 